\title{
Genome-wide screen uncovers novel pathways for tRNA processing and nuclear-cytoplasmic dynamics
}

\author{
Jingyan Wu, ${ }^{1,2,3}$ Alicia Bao, ${ }^{1}$ Kunal Chatterjee, ${ }^{1,2}$ Yao Wan, ${ }^{1,2}$ and Anita K. Hopper ${ }^{1,2}$ \\ ${ }^{1}$ Department of Molecular Genetics, ${ }^{2}$ Center for RNA biology, The Ohio State University, Columbus, Ohio 43210, USA
}

Transfer ribonucleic acids (tRNAs) are essential for protein synthesis. However, key gene products involved in tRNA biogenesis and subcellular movement remain to be discovered. We conducted the first comprehensive unbiased analysis of the role of nearly an entire proteome in tRNA biology and describe 162 novel and 12 previously known Saccharomyces cerevisiae gene products that function in tRNA processing, turnover, and subcellular movement. tRNA nuclear export is of particular interest because it is essential, but the known tRNA exporters (Los1 [exportin-t] and Msn5 [exportin-5]) are unessential. We report that mutations of CRM1 (Exportin-1), MEX67/MTR2 (TAP/p15), and five nucleoporins cause accumulation of unspliced tRNA, a hallmark of defective tRNA nuclear export. CRM1 mutation genetically interacts with $\operatorname{los} 1 \Delta$ and causes altered tRNA nuclear-cytoplasmic distribution. The data implicate roles for the protein and mRNA nuclear export machineries in tRNA nuclear export. Mutations of genes encoding actin cytoskeleton components and mitochondrial outer membrane proteins also cause accumulation of unspliced tRNA, likely due to defective splicing on mitochondria. Additional gene products, such as chromatin modification enzymes, have unanticipated effects on pre-tRNA end processing. Thus, this genome-wide screen uncovered putative novel pathways for tRNA nuclear export and extensive links between tRNA biology and other aspects of cell physiology.

[Keywords: genome-wide screen; tRNA trafficking; Crm1; tRNA processing]

Supplemental material is available for this article.

Received August 5, 2015; revised version accepted November 11, 2015.

Transfer ribonucleic acids (tRNAs) are essential components of the protein synthesis machinery in all kingdoms of life, as they bring amino acids to ribosomes during translation. tRNAs are also involved in many critical processes, including cellular responses to stress, protein degradation, apoptosis, and retrovirus replication (Phizicky and Hopper 2010). Moreover, defects in tRNA processing are responsible for numerous human disorders (Kirchner and Ignatova 2015). The important roles of tRNAs have highlighted a need for a complete understanding of the steps that affect tRNA processing and subcellular dynamics.

To date, 94 gene products that participate in tRNA posttranscriptional processing have been identified in Saccharomyces cerevisiae. Seventy-three are involved in the 25 known tRNA nucleotide modifications, and 21 are in-

\footnotetext{
${ }^{3}$ Present address: Department of Genetics, School of Medicine, Stanford University, Palo Alto, CA 94305, USA.

Corresponding author: hopper.64@osu.edu

Article is online at http://www.genesdev.org/cgi/doi/10.1101/gad.269803. 115 .
}

volved in tRNA end processing and splicing (Hopper 2013; Sharma et al. 2015). Moreover, there are numerous additional genes encoding proteins that function in tRNA turnover and nuclear-cytoplasmic dynamic pathways that are shared with other types of RNA (Hopper 2013; Takano et al. 2015).

Although genes involved in tRNA biology have been studied extensively, many aspects of tRNA processing and subcellular dynamics remain unclear (Fig. 1A). For example, RNA polymerase III (Pol III) mediates tRNA transcription, but so far only a single yeast Pol III regulator, Maf1, has been identified (Pluta et al. 2001), and it is not clear whether other regulators exist. After tRNA transcription, endonucleases RNase $\mathrm{P}$ and RNase $\mathrm{Z}$ and exonucleases catalyze tRNA leader and trailer removal

(C) $2015 \mathrm{Wu}$ et al. This article is distributed exclusively by Cold Spring Harbor Laboratory Press for the first six months after the full-issue publication date (see http://genesdev.cshlp.org/site/misc/terms.xhtml). After six months, it is available under a Creative Commons License (Attribution-NonCommercial 4.0 International), as described at http:// creativecommons.org/licenses/by-nc/4.0/. 
Wu et al.

A

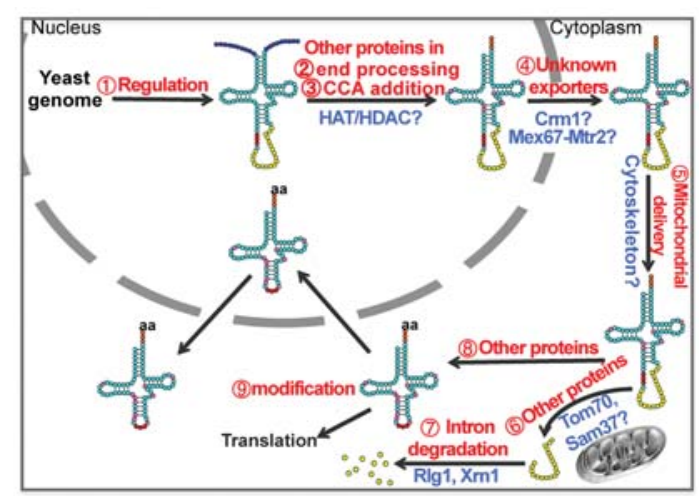

B

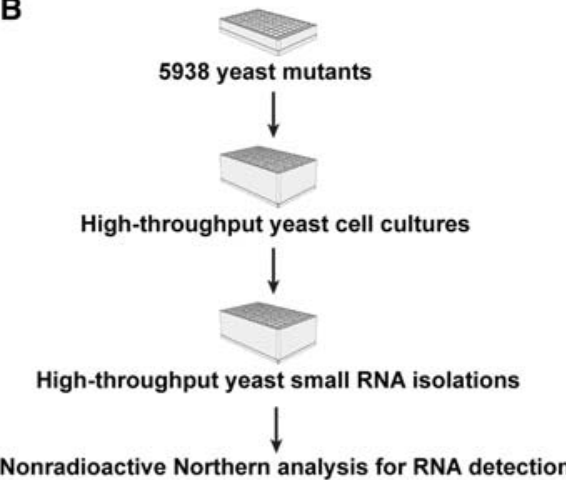

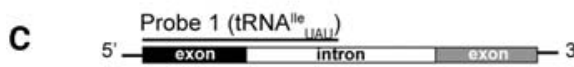
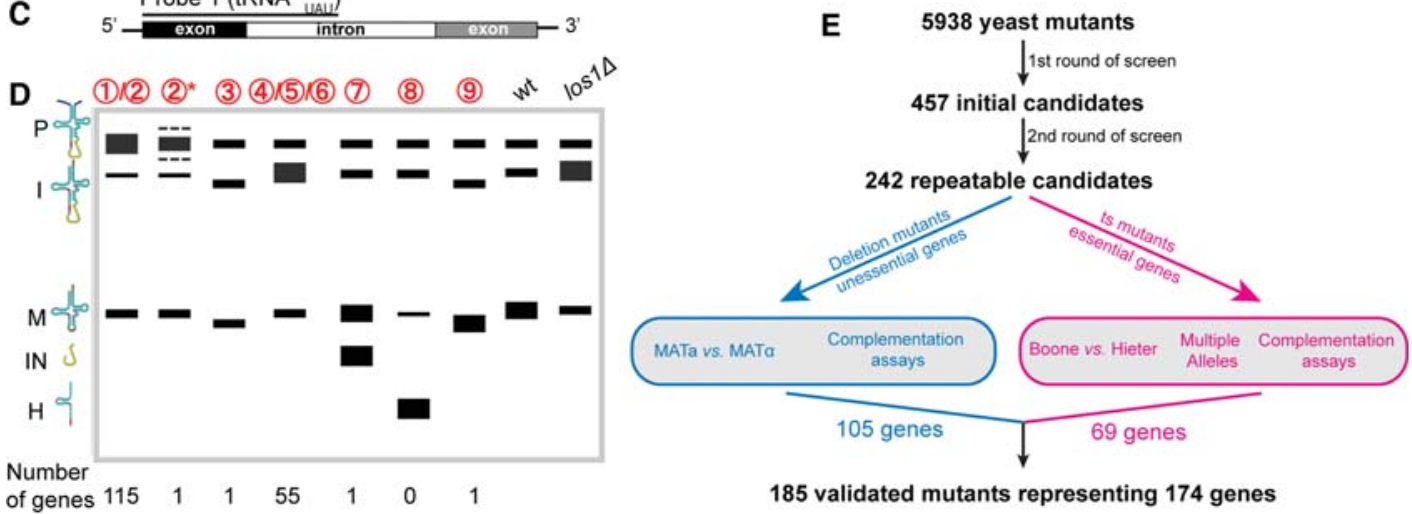

185 validated mutants representing 174 genes

Figure 1. Genome-wide screen for novel gene products involved in tRNA biology. (A) Many key gene products involved in tRNA biogenesis and subcellular movement have not been identified. The steps that likely have missing gene products are highlighted by red numbers. Some of the novel gene products identified by this screen are highlighted in blue. $(B)$ Scheme for genome-wide screening procedures. (C) A schematic view of a primary tRNA ${ }_{\text {UAU }}^{\text {Ile }}$ transcript with $5^{\prime}$ leader, $3^{\prime}$ trailer, exons, and intron and probe 1 used for Northern hybridization. $(D)$ Expected phenotypes of mutants that are defective in different processes of tRNA biology by Northern analysis of tRNA ${ }_{\text {UAU }}^{\text {Ile }}$ Lane $2^{*}$ indicates defects in exonucleolytic $3^{\prime}$ end trimming. (P) Primary tRNA transcript, 145 nucleotides (nt); (I) end-matured intron containing tRNA, $136 \mathrm{nt}$; (M) mature tRNA, $76 \mathrm{nt}$; (IN) intron, $60 \mathrm{nt}$; $(\mathrm{H}) 5^{\prime}$ exon, $37 \mathrm{nt}$. Numbers below each lane indicate the number of mutants discovered for each phenotype. (E) Strategies for candidate validation for unessential genes (blue) and essential genes (pink). (ts) Temperature sensitive.

(Frank and Pace 1998; Skowronek et al. 2014), and tRNA nucleotidyltransferase Ccal adds the CCA sequence to the $3^{\prime}$ end (Aebi et al. 1990). It is unknown whether there are additional enzymes or regulators for the end processing steps. In yeast, but not in vertebrate cells, end-processed, partially modified, intron-containing tRNAs are exported to the cytoplasm. Los1 is the only known exporter for initial nuclear export of intron-containing tRNAs (Hopper et al. 1980; Murthi et al. 2010; Huang and Hopper 2015). However, los $1 \Delta$ cells are healthy (Hurt et al. 1987), indicating that there must be other unknown pathways for tRNA export. Since the tRNA splicing endonuclease (SEN) complex is located on the mitochondrial outer surface (Yoshihisa et al. 2003), intron-containing tRNAs must travel to mitochondria for intron removal. Introncontaining tRNAs are barely detectable in the cytoplasm (Sarkar and Hopper 1998), implicating efficient localization of tRNAs to mitochondria. Nonetheless, gene products that would function in tRNA cytoplasmic movement have not been discovered. Furthermore, little is known about the mechanisms for regulating the proper mitochondrial localization of the SEN complex. In addition, two tRNA degradation pathways for destroying tRNAs with defects in modification and/or stability have been uncovered (Kadaba et al. 2004; Chernyakov et al. 2008), and it is plausible that there might be other missing proteins for degradation of tRNA and their processing intermediates and byproducts.

In order to identify gene products that function in tRNA production, processing, degradation, and subcellular movement, we conducted an unbiased genome-wide screen of nearly all annotated genes in S. cerevisiae. We used one yeast haploid deletion collection (Winzeler et al. 1999) and two temperature-sensitive collections (Ben-Aroya et al. 2008; Li et al. 2011) to identify mutants with defects in tRNA processing. Previously, we reported that Xrn1, found by this screen, is a key component of the mechanism for tRNA intron turnover (Wu and Hopper 2014). Here, we provide the results of the entire screen that uncovered 162 novel gene products involved in various tRNA biology processes. These include nuclear pore complex (NPC) proteins, tRNA-aminoacyl synthetases 
(aaRS), cytoskeleton components, mitochondrial membrane proteins, and mRNA/ribosome export machinery. Importantly, we found that the Ran GTPase-dependent karyopherin Crm1/Xpol may provide a novel pathway for nuclear export of intron-containing tRNAs.

\section{Results}

Genome-wide screen to identify novel gene products involved in $t$ RNA biology

To systematically identify gene products that function in tRNA biology (Fig. 1A), we conducted a genome-wide screen of nearly all annotated essential and unessential protein-encoding genes in S. cerevisiae. The yeast genome contains 6604 verified and dubious protein-encoding genes (YeastMine, Saccharomyces Genome Database, http://www.yeastgenome.org; Cherry et al. 2012). We analyzed mutants from three yeast collections: the yeast MATa haploid collection that contains deletions of 4847 unessential protein-coding genes (Winzeler et al. 1999), a collection created by Boone and coworkers ( $\mathrm{Li}$ et al. 2011) that contains 757 temperature-sensitive alleles of 476 essential genes, and a collection generated by Hieter and coworkers (Ben-Aroya et al. 2008) that contains 333 temperature-sensitive alleles of 332 essential genes. Together, these collections contain nearly all annotated unessential genes and 765 of 1105 (73.1\%) annotated essential genes (Giaever et al. 2002), which in total comprise at least $85.0 \%$ of the yeast ORFs.

To conduct this genome-wide screen, we developed a method that consists of culturing yeast in 96-deep-well plates, a fast procedure for isolation of low-molecularweight RNAs from the cultures, and a nonradioactive Northern blot method for RNA detection (Fig. 1B; Wu et al. 2013). We chose to detect one tRNA encoded by an intron-containing gene, tRNA ${ }^{\text {Ile }}{ }_{U A U}$, as it contains the largest intron (60 nucleotides [nt]), and its various processing intermediates have distinct sizes, thereby allowing assessment of all processing intermediates, byproducts, and mature tRNAs in single gel lanes. A probe complementary to the whole $5^{\prime}$ exon and nucleotides 1-30 of the intron (probe 1) was designed (Fig. 1C) to detect the primary tRNA transcript $(\mathrm{P})$, end-matured intron-containing tRNA (I), mature tRNA (M), free introns (IN), tRNA halves $(\mathrm{H})$, and other possible species (Fig. 1D). RNAs were extracted from cells with deletions of unessential genes grown in rich medium at $23^{\circ} \mathrm{C}$ and cells with temperature-sensitive mutations after a 2 -h shift to the nonpermissive temperature $\left(37^{\circ} \mathrm{C}\right)$.

Defects in any of the tRNA processing steps (numbered in Fig. 1A) are predicted to alter migration of tRNA species on polyacrylamide gels (Fig. 1D). Figure 2 provides example Northern analyses of some of the identified mutants illustrated in Figure 1D. A mutant with increased transcription of the initial transcripts (Fig. 1A, step 1) is expected to accumulate species $\mathrm{P}$ (Figs. 1D [lanes 1,2], 2A [for a possible example]). A mutant defective in $5^{\prime}$ or $3^{\prime}$ end processing (Fig. 1A, step 2) will accumulate $\mathrm{P}$ or species above or below $\mathrm{P}$ (Figs. 1D [lanes 1,2 or 2*], 2B,C). A

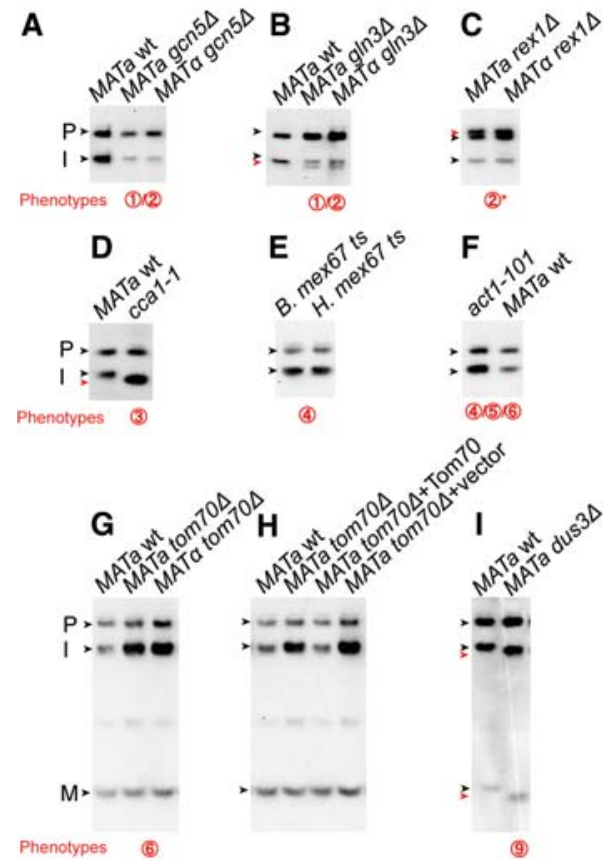

Figure 2. Example mutants defective in tRNA biology. Northern analysis of tRNA ${ }^{\text {Ile }}$ UAU for mutants that demonstrate defects indicated in Figure 1, A and D. (P) Primary tRNA transcript; (I) end-matured intron-containing tRNA; $(M)$ mature tRNA. Aberrant tRNA species are highlighted with red arrowheads.

mutant defective in CCA addition to the $3^{\prime}$ end (Fig. 1A, step 3) will accumulate a RNA species that migrates slightly faster than CCA-containing tRNAs (Figs. 1D [lane 3], 2D). Defects in initial nuclear export of tRNAs, delivery of tRNAs to the mitochondrial surface, or incorrect localization, assembly, or function of the SEN complex (Fig. 1A, steps 4, 5, or 6) will accumulate endmatured intron-containing tRNAs (I) (Figs. 1D [lanes 4,5,6], 2E-G [putative mutants]). We previously reported discovery of mutants that are defective in intron turnover (Fig. 1A, step 7), as Xrn1 $\Delta$ and rlg1-4 mutant cells accumulate free introns (IN) (Fig. 1D, lane 7; Wu and Hopper 2014). Finally, a mutant that affects tRNA modification (Fig. 1A, step 9) may demonstrate altered migration of mature tRNAs and their processing intermediates (Figs. 1D [lane 9], 2I). los1 $\Delta$ or sen2-42 cells, which accumulate end-matured intron-containing tRNA, and wild-type cells served as controls for the screen (Fig. 1D).

After the first round of the screen, 457 mutants were identified whose mutation led to tRNA processing defects. A second round of Northern analysis was performed for all initial mutants, and 242 candidates that had repeatable phenotypes were further validated. Since the yeast collections contain annotation errors or second site mutations (Grunenfelder and Winzeler 2002; Ben-Shitrit et al. 2012), the candidates were subjected to additional verification (Fig. 1E).

In the third round of the screen, candidates from the MATa haploid deletion collections were compared with the strain containing a deletion of the same gene in the 
independently constituted MATa deletion collection (Figs. 1E, 2A-C,G for examples; Giaever et al. 2002). A candidate was considered verified if the corresponding mutant in the MATa deletion collection showed the same phenotype. Among verified deletion mutants, six were further confirmed by introduction of the yeast genomic tiling plasmid containing the corresponding wildtype gene (Jones et al. 2008) to assess whether the wildtype gene complements the mutant phenotype (Figs. 1E, $2 \mathrm{H}$ [for an example]; Supplemental Table S1). A total of 105 genes were validated, representing $2.2 \%$ of all unessential genes screened (Supplemental Table $S 1$; see primary data in Supplemental Fig. S1).

To verify candidates from the Boone temperature-sensitive mutant collection (Li et al. 2011), three approaches were used (Fig. 1E). First, the Hieter laboratory (Ben-Aroya et al. 2008) generated numerous temperature-sensitive mutants by transferring mutant alleles from the Boone collection (Li et al. 2011) into the Hieter collection genetic background. If the same allele in two different genetic backgrounds demonstrated the same phenotype, this mutant allele was considered as verified (see Fig. 2E for an example and primary data for all mutants in Supplemental Fig. S2). Second, several gene candidates have multiple alleles available. If different alleles of the same gene confer the same phenotype (Supplemental Table S2; Supplemental Fig. S2), it strongly supports the notion that this gene plays a role in tRNA biology. Third, the remaining mutants that do not have either the same allele in different genetic backgrounds or multiple alleles were assessed by complementation assays using the vectors from the yeast genomic tiling collection (Jones et al. 2008) and/or the Molecular Barcoded Yeast ORF (MoBY-ORF) library (Ho et al. 2009) (Supplemental Table S2). Using these approaches, 60 temperature-sensitive alleles of 50 essential genes were verified to affect tRNA biology (Supplemental Table S2), representing $10.5 \%$ of the 476 genes in the Boone collection.

Candidates identified in the Hieter temperature-sensitive collection were analyzed by complementation assays (Fig. 1E). Since the strains in the Hieter temperature-sensitive collection do not harbor the nutritional markers required for complementation tests using the available genome-wide library plasmid collections (Ben-Aroya et al. 2008), we selected for $\mathrm{Ura}^{-}$variants for the candidates using 5-fluoroorotic acid selection (Boeke et al. 1984). The resulting ura3 mutants with temperature-sensitive alleles affecting tRNA biology were transformed with the MoBYORF vectors that contain wild-type versions of the relevant genes, and complementation was assessed by Northern analyses. This resulted in 20 validated mutants (Supplemental Table S3; see Northern analyses in Supplemental Fig. S3), representing $6.0 \%$ of the genes in the Hieter temperature-sensitive collection.

In summary, through this genome-wide screen, we identified 174 genes whose mutations affect tRNA migration by Northern analysis, screened by biological repeats, and validated with independent mutants and/or complementation assays (Supplemental Tables S1-S3; Supplemental Figs. S1-S3). Forty percent of the identified genes are essential genes, and 60\% are unessential (Fig. 3A). However, there is a significantly higher percentage of essential genes identified from the temperature-sensitive collections $(10.5 \%$ from the Boone and $6.0 \%$ from the Hieter collections) than unessential genes from the deletion collection (2.2\%).

Among the 174 identified genes, 12 were previously known to be involved in tRNA processing, modification, intron removal, and transport (Fig. 3B), whereas 162 are novel genes not known previously to affect levels of processing intermediates and/or migration of tRNAs. Functional gene ontology (GO) analysis of the 174 identified genes revealed a clear enrichment in RNA transport and nucleocytoplasmic transport factors. Other enriched GO categories include macromolecular complex subunit organization, chromatin modification, and establishment of ribosome localization (Fig. 3C), suggesting possible links between tRNA biology and these cellular processes. As expected, molecular functions related to RNA metabolic process were significantly enriched in the GO analysis (Fig. 3C).

\section{Novel gene products in tRNA nuclear-cytoplasmic trafficking}

Among the nucleocytoplasmic transport factors identified, there is an overrepresentation of NPC and the RanGTPase cycle proteins (Table 1). Nuclear pores are the portals of the nuclear envelope for nuclear-

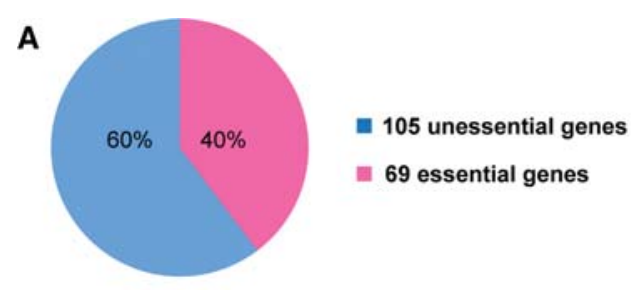

B

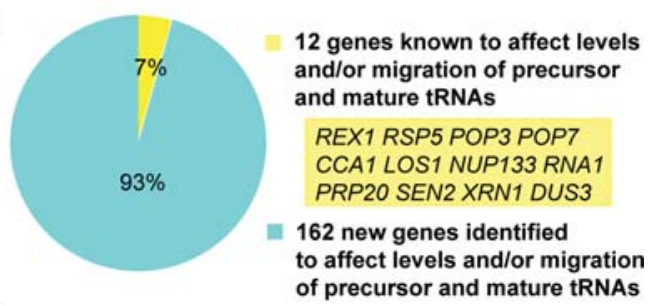

C

\begin{tabular}{|llc|}
\hline Molecular and collular function & P.Value & \#hits \\
\hline RNA transport & $1.14 \mathrm{E}-06$ & 20 \\
\hline Nucleocytoplasmic transport & $2.64 \mathrm{E}-06$ & 23 \\
\hline Macromolecular complex subunit organization & $3.3 \mathrm{E}-02$ & 49 \\
\hline Chromatin organization & $5.15 \mathrm{E}-03$ & 24 \\
\hline Establishment of ribosome localization & $2.73 \mathrm{E}-02$ & 9 \\
\hline RNA metabolic process & $2.47 \mathrm{E}-03$ & 71 \\
\hline
\end{tabular}

Figure 3. Novel gene products in tRNA biology. (A) Unessential and essential genes identified that affect tRNA biology. (B) Previously known and novel genes identified. $(C)$ Functional gene ontology (GO) term enrichment for the validated 174 genes. The statistical significance of the enrichment (YeastMine, Saccharomyces Genome Database, http://www.yeastgenome.org) and the number of hits in each category are indicated. 
Table 1. Discovered gene products in tRNA nuclear-cytoplasmic transport

\begin{tabular}{|c|c|c|c|c|}
\hline Gene & $\begin{array}{l}\text { Essential/ } \\
\text { unessential }\end{array}$ & $\begin{array}{l}\text { Mutant } \\
\text { phenotypes }^{\mathrm{a}}\end{array}$ & $\begin{array}{l}\text { Northern data location (figure number and } \\
\text { gel number) }\end{array}$ & References \\
\hline \multicolumn{5}{|c|}{$\begin{array}{l}\text { NPC and nuclear } \\
\text { envelope proteins }\end{array}$} \\
\hline$N D C 1$ & Essential & Type $4 / 5 / 6$ & $\begin{array}{l}\text { Supplemental Fig. S2, ABGel 73; } \\
\quad \text { Supplemental Fig. S2-1, ABGel } 92\end{array}$ & This study \\
\hline NUP57 & Essential & Type $4 / 5 / 6$ & Supplemental Fig. S3 & This study \\
\hline NUP133 & Unessential & Type $4 / 5 / 6$ & Supplemental Fig. S1-2, JWGel 192 & $\begin{array}{l}\text { Sharma et al. } \\
1996\end{array}$ \\
\hline NUP159 & Essential & Type $4 / 5 / 6$ & $\begin{array}{l}\text { Supplemental Fig. S2, ABGel 79; } \\
\text { Supplemental Fig. S2-1, ABGel } 92\end{array}$ & This study \\
\hline NUP170 & Unessential & Type $4 / 5 / 6$ & Supplemental Fig. S1-2, JWGel 191 & This study \\
\hline NUP192 & Essential & Type $4 / 5 / 6$ & Supplemental Fig. S2, ABGel 74 & This study \\
\hline SEC13 & Essential & Type $4 / 5 / 6$ & Supplemental Fig. S2, ABGel 72 & This study \\
\hline$B R L 1$ & Essential & Type $4 / 5 / 6$ & Supplemental Fig. S2-1, ABGel 118 & This study \\
\hline \multicolumn{5}{|c|}{ Ran GTPase cycle } \\
\hline RNA1 & Essential & Type $4 / 5 / 6$ & Supplemental Fig. S2, ABGel 73 & $\begin{array}{l}\text { Hopper et al. } \\
1978\end{array}$ \\
\hline PRP20/SRM1 & Essential & Type $4 / 5 / 6$ & Supplemental Fig. S2, ABGel 81 & $\begin{array}{l}\text { Kadowaki et al. } \\
1993\end{array}$ \\
\hline$Y R B 1$ & Essential & Type $4 / 5 / 6$ & Supplemental Fig. S2, ABGel 79 & This study \\
\hline \multicolumn{5}{|l|}{$\begin{array}{l}\text { mRNA export } \\
\text { machinery }\end{array}$} \\
\hline MEX67 & Essential & Type $4 / 5 / 6$ & Fig. 2E; Supplemental Fig. S2, ABGel 81 & This study \\
\hline MTR2 & Essential & Type $4 / 5 / 6$ & Supplemental Fig. S3 & This study \\
\hline \multicolumn{5}{|c|}{ Importin- $\beta$ proteins } \\
\hline CRM1 & Essential & Type $4 / 5 / 6$ & Fig. 4; Supplemental Fig. S2-1, ABGel 83 & This study \\
\hline LOS1 & Unessential & Type $4 / 5 / 6$ & NA & $\begin{array}{l}\text { Hopper et al. } \\
1980\end{array}$ \\
\hline
\end{tabular}

${ }^{a}$ See Figure 1 for an explanation of type 4/5/6. (NA) Not applicable, as los $1 \Delta$ is a control for numerous gels.

cytoplasmic transport of proteins and RNAs. Previous studies reported that mutations of genes encoding five nuclear pore proteins (Nups; Nup49, Nup116, Nup145, Nup133, and Nsp1) cause accumulation of intron-containing tRNAs, whereas mutations of three others (Nup1, Nup85, and Nup100) have no apparent effect on pretRNA splicing (Sharma et al. 1996; Simos et al. 1996). Of the 30 genes encoding Nups (Wente and Rout 2010), 22 are available in the mutant collections that we screened. Consistent with previous reports, nup133 $\Delta$ but not nup1 1 , nup $85 \Delta$, or nup $100 \Delta$ cells accumulate introncontaining tRNA ${ }_{\text {UAU; }}^{\text {Ile }}$ Nup49, Nup116, Nup145, and Nsp1 are not represented in the mutant collections. Interestingly, cells harboring mutations of genes encoding five additional Nups (Ndc1, Nup57, Nup159, Nup170, and Nup192), previously unknown to affect tRNA splicing, accumulate intron-containing tRNA ${ }^{\text {Ile }}$ UAU (see Supplemental Figs. S1-S3). Mutants harboring four different alleles of the nuclear envelop protein Brll also cause accumulation of unspliced tRNA (Supplemental Fig. S2). The combined current and previous analyses show that mutations of 10 of the 26 assayed genes encoding mutant Nups affect pre-tRNA splicing (Table 1; Supplemental Figs. S1-S3).

The small GTPase Ran is required for nuclear-cytoplasmic transport of most macromolecules /Gorlich and Kutay 1999). In yeast, the Ran GTPase system includes the GTPase Ran encoded by GSP1 and GSP2, the Ran GTPase-activating protein encoded by $R N A 1$, the Ran guanine nucleotide exchange factor RCC1 encoded by PRP20/SRM1, and the Ran-binding protein RanBP1 encoded by $Y R B 1$. We did not observe tRNA processing defects for the deletion mutants of either GSP1 or GSP2, likely due to their functional redundancy. However, we identified the other three genes, RNA1, PRP20/SRM1, and $Y R B 1$, whose mutations cause the same phenotype - accumulation of end-matured intron-containing tRNAs (Table 1; Supplemental Fig. S2). Previous studies reported that mutation of RNA1 (rna1-1) and PRP20 causes accumulation of intron-containing pre-RNAs (Hopper et al. 1978; Kadowaki et al. 1993; Sarkar and Hopper 1998). Our results show, in addition, that Yrb1 is required for tRNA splicing.

We also identified two members of the importin- $\beta$ family, Los 1 and Crm1 (also called Xpo1; vertebrate exportin-1) (Table 1; Fig. 4). los1 $\Delta$ cells accumulate end-processed intron-containing tRNAs in the nucleus (Hopper et al. 1980; Sarkar and Hopper 1998; Murthi et al. 2010), and, as anticipated, we uncovered $\operatorname{los} 1 \Delta$ as a mutant that is defective in pre-tRNA splicing.

The Ran GTPase-dependent karyopherin Crm1/Xpol may provide a second nuclear export pathway. Crm 1 functions in nuclear export of proteins with leucine-rich nuclear export signals, preribosomes, and telomerase RNA (Fornerod et al. 1997; Stade et al. 1997; Woolford and Baserga 2013; Wu et al. 2014). Through our screen, we learned that crm1-1 cells accumulate end-matured 
intron-containing tRNA ${ }^{\text {Ile }}$ UAU and $\mathrm{tRNA}^{\mathrm{Tyr}}$ at the nonpermissive temperature (Fig. 4A,B). To verify the phenotype of crm1-1 cells identified in the Boone collection (B. crm1-1), we analyzed other strains that contain the same crm1-1 allele in different genetic backgrounds: the crm1-1 mutant in the Hieter temperature-sensitive collection background (H. crm 1-1) and the original xpo1-1 allele (xpo1-1) (Stade et al. 1997). Northern analysis shows that RNAs isolated from crm1-1 temperature-sensitive strains grown at $23^{\circ} \mathrm{C}$ generally possess slightly elevated levels of end-processed intron-containing tRNAs compared with wild-type and rna1-1 cells (Fig. 4A,B, cf. lanes $2,3,4$ and 1,5$)$. After the shift to the nonpermissive temperature $\left(37^{\circ} \mathrm{C}\right)$ for $2 \mathrm{~h}$, there was no change in the distribution of tRNA species in wild-type cells (Fig. 4A,B, lanes 6). However, the three crm 1-1 temperature-sensitive strains as well as the rna1-1 strain (Fig. 4A,B, lanes 7-10) accumulated elevated levels of end-matured introncontaining tRNAs (I) as compared with the initial transcripts $(\mathrm{P})$.

We validated that accumulation of species $\mathrm{I}$ is due to mutation of CRM1 by complementation assays. When Crm1 was exogenously expressed in crm1-1 cells from a multicopy plasmid (Jones et al. 2008), the level of end-matured intron-containing pre-tRNA ${ }_{\text {UAU }}^{\text {Ile }}$ returned to the level observed in wild-type cells, whereas crm1-1 cells transformed with vector alone accumulated end-matured intron-containing tRNA ${ }_{\text {UAU }}^{\text {Ile }}$ (Fig. 4C, cf. lanes 3,7 and
$4,8)$. The growth defect of crm1-1 cells after temperature shift was also complemented (Supplemental Fig. S4). The data provide evidence that Crm 1 affects tRNA biogenesis.

To determine whether the observed phenotype of crm11 may be an indirect consequence of exposing the mutant cells to $37^{\circ} \mathrm{C}$ for $2 \mathrm{~h}$, we analyzed RNAs from cells exposed to $37^{\circ} \mathrm{C}$ for shorter times. crm 1-1 cells accumulated endmatured intron-containing tRNAs after the shift to $37^{\circ} \mathrm{C}$ for $30 \mathrm{~min}$ (Fig. 4D). The rapid effect on tRNAs indicates that Crm1 may play a direct role in tRNA nuclear export.

If Crm 1 functions in parallel with Los 1 to export introncontaining tRNA to the cytoplasm, there may be genetic interactions between crm1-1 and los $1 \Delta$. To test this, we used a crm1-1 los $1 \Delta$ double mutant and assessed growth at various temperatures. At $23^{\circ} \mathrm{C}$, the two single mutants (crm1-1 and los1 1 ) and the crm1-1 los1 $\Delta$ double mutant grew similarly to wild-type cells. The double mutant crm1-1 los1 $\Delta$ cells grew less well than wild-type cells at $30^{\circ} \mathrm{C}$. Importantly, although both single mutants $(\mathrm{crm} 1$ 1 and los $1 \Delta$ ) are viable at $34^{\circ} \mathrm{C}$, the double mutant crm1-1 los $1 \Delta$ did not grow at $34^{\circ} \mathrm{C}$ (Fig. 4E), indicating that LOS1 genetically interacts with CRM1. The data demonstrate that cells are not viable if both pathways are blocked, further supporting that Crm1 may function in parallel with Los 1 in tRNA nuclear export.

If Crm 1 is involved in tRNA nuclear export, loss of its function should cause tRNA nuclear accumulation. We therefore evaluated the subcellular location of $\mathrm{tRNA}^{\mathrm{Tyr}}$
A
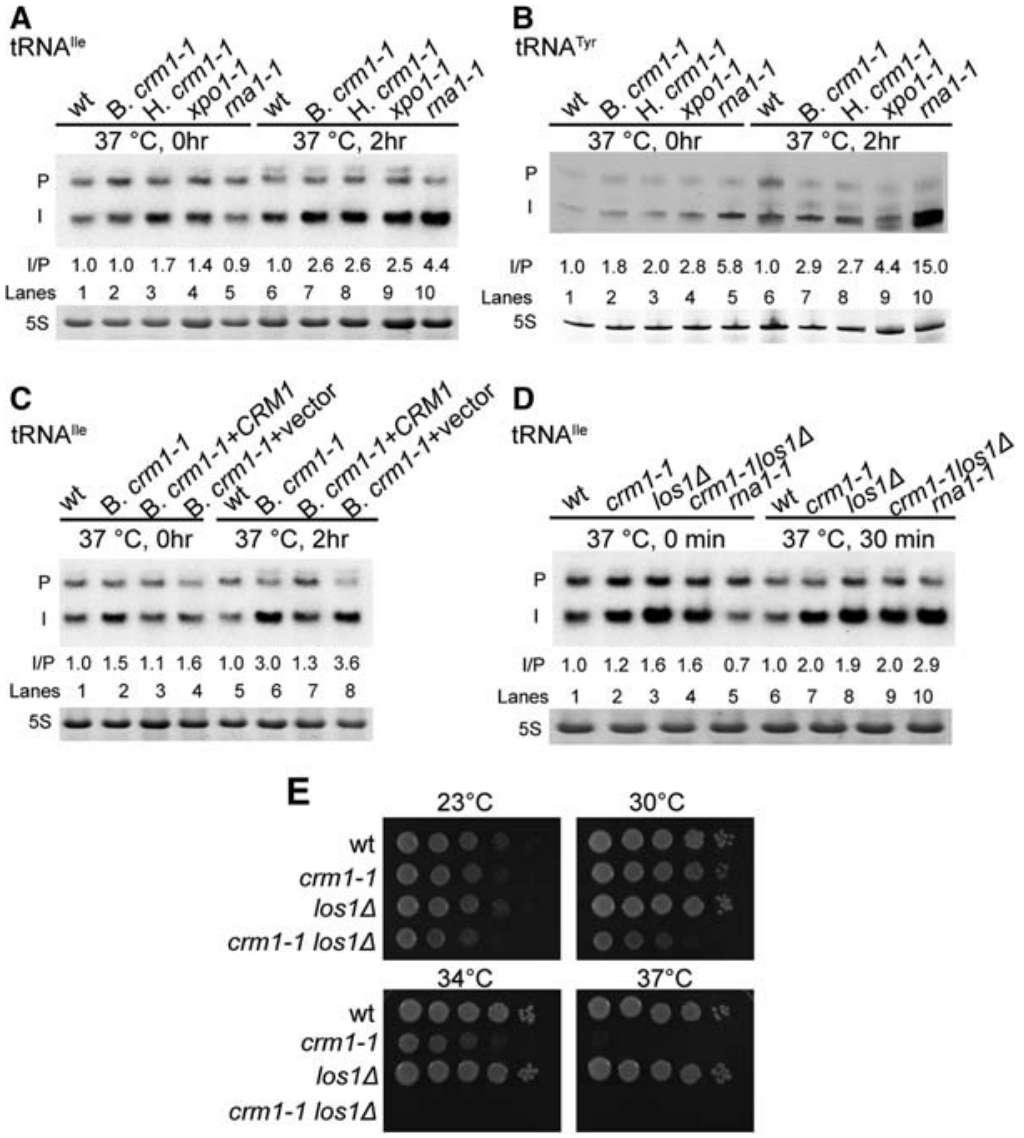

Figure 4. Crm1 is likely a new nuclear exporter for intron-containing tRNAs. (A) Temperature-sensitive mutation of the CRM1 gene leads to accumulation of end-matured intron-containing tRNA ${ }_{\text {UAU. North- }}^{\text {Ile }}$ ern analysis of RNAs from wild-type, rna1-1, and crm1-1 strains of different genetic backgrounds was performed using probe 1 for $\mathrm{tRNA}^{\text {Ile }}$ UAU. $(\mathrm{I} / \mathrm{P})$ Ratio of species I divided by $\mathrm{P}$ and normalized to wildtype cells grown under the same conditions. $(B)$ Temperature-sensitive mutation of the CRM1 gene leads to accumulation of end-matured intron-containing tRNA $^{\text {Tyr }}$. Northern analysis of RNAs from wildtype, rna1-1, and crm1-1 strains of different genetic backgrounds was performed using probe KC031. (I/ P) Ratio of species I divided by $\mathrm{P}$ and normalized to wild-type cells grown under the same conditions. (C) Complementation of the crm1-1 temperaturesensitive phenotype by YEpCrm1. Northern analysis of RNAs from wild-type cells, Boone collection crm1-1 cells, and Boone collection crm1-1 cells transformed with YEpCrm 1 or vector was performed using probe 1 . (D) Northern analysis of RNAs from

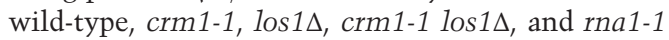
cells after $30 \mathrm{~min}$ of incubation at $37^{\circ} \mathrm{C}$ using probe 1. (E) Genetic interactions between LOS1 and CRM1. Serial dilutions of wild-type, $\operatorname{crm} 1-1, \operatorname{los} 1 \Delta$, and crm1-1 los $1 \Delta$ cells were applied to YEPD medium, and the plates were incubated for $2 \mathrm{~d}$ at $23^{\circ} \mathrm{C}$, $30^{\circ} \mathrm{C}, 34^{\circ} \mathrm{C}$, and $37^{\circ} \mathrm{C}$. 
in crm1-1, wild-type, and rna1-1 cells by fluorescence in situ hybridization (FISH). As expected, wild-type cells after the shift to $37^{\circ} \mathrm{C}$ for 0,2 , or 4 h exhibited an even distribution of tRNA ${ }^{\mathrm{Tyr}}$ throughout cells (Fig. 5, top row). rna1-1 cells exhibited nucleoplasmic accumulation of tRNA $^{\text {Tyr }}$ after 2 or $4 \mathrm{~h}$ at $37^{\circ} \mathrm{C}$, as previously reported (Fig. 5, middle row; Sarkar and Hopper 1998). Surprisingly, for crm 1-1 cells after the shift to $37^{\circ} \mathrm{C}$ for $2 \mathrm{~h}$, the nucleoplasm appeared void of signal, and some cells accumulated tRNA ${ }^{\text {Tyr }}$ at the nuclear periphery (Fig. 5, bottom row, example cells are marked with arrowheads). After $4 \mathrm{~h}$ at $37^{\circ} \mathrm{C}$, most of the cells demonstrated tRNA ${ }^{\text {Tyr }}$ accumulation at the nuclear periphery (Fig. 5, bottom row, example cells are marked with arrowheads). A similar nuclear peripheral location in crm1-1 cells was observed using a probe complementary to tRNA ${ }^{\text {Ile }}$ UAU mature sequences (SRIM04) (Supplemental Material), although the signals were weaker, likely due to low tRNA expression (two tRNA $^{\text {Ile }}$ UAU genes vs. eight tRNA ${ }^{\text {Tyr }}$ genes) (Supplemental Fig. S5A). We also attempted to locate only intron-containing pre-tRNA using a probe complementary to the tRNA ${ }^{\text {Ile }}$ UAU intron (SRIM03) (Supplemental Material). Although the signals are weak, the rna1-1 signal is nucleoplasmic before and after the shift to $37^{\circ} \mathrm{C}$, whereas the signal for crm1-1 cells is nucleoplasmic before the shift to $37^{\circ} \mathrm{C}$ and is both nucleoplasmic and spread to the nuclear periphery after the shift to $37^{\circ} \mathrm{C}$ (Supplemental Fig. $\mathrm{S} 5 \mathrm{~B})$. Thus, loss of Crm1 function appears to cause tRNAs to accumulate at the nuclear periphery instead of the nucleoplasm. Together, the data support a role for Crm1 in tRNA nuclear/cytoplasmic dynamics.

We also identified the two components of the general mRNA nuclear exporter heterodimer Mex67/Mtr2 (vertebrate TAP/p15) that mediates translocation of mRNAs through the NPC (Nino et al. 2013), as their mutants accumulate end-processed intron-containing tRNAs at the nonpermissive temperature (Table 1; Fig. 2E; Supplemental Figs. S2, S3; Supplemental Tables S2, S3). Further stud-

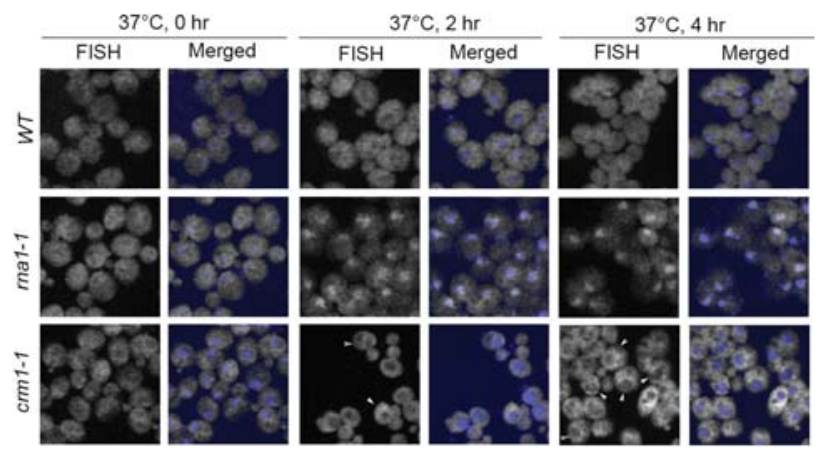

Figure 5. tRNAs accumulate at the nuclear periphery in crm1-1 cells. Wild-type, rna1-1, and crm $1-1$ cells were cultured at $23^{\circ} \mathrm{C}$, shifted to $37^{\circ} \mathrm{C}$, and harvested at 0,2 , and $4 \mathrm{~h}$ after the temperature shift. The subcellular localization of tRNA ${ }^{\mathrm{Tyr}}$ was examined by FISH using probe SRIM15. Nuclei were visualized by DAPI staining of DNA (highlighted in blue in the merged panels). Arrowheads highlight example cells with tRNA signal at the nuclear periphery. ies are required to address the possibility that Mex67/ Mtr2 serves as yet another nuclear export pathway for intron-containing tRNAs.

\section{Possible dynamics of $t R N A$ s and SEN in the cytoplasm}

We identified categories of mutants that accumulate endprocessed unspliced tRNA ${ }^{\text {Ile }}$ UAU, possibly due to defects in tRNA dynamics post-nuclear export to the cytoplasm. The first category includes mutations of genes encoding actin cytoskeleton components ACT1, MYO2, and PFY1 (Table 2; Fig. 2F; Supplemental Fig. S2). Since, upon nuclear export, intron-containing tRNAs must localize to mitochondria for splicing, but intron-containing tRNAs are nearly undetectable in the cytoplasm (Sarkar and Hopper 1998), there may be a mechanism to rapidly deliver tRNAs to mitochondria. As there is extensive precedence for the role of the actin cytoskeleton in RNA subcellular transport (Buxbaum et al. 2015), one possible role for Act1, Myo2, and Pfy1 in tRNA processing is to deliver intron-containing tRNAs to mitochondria.

The second category of genes possibly involved in tRNA cytoplasmic processing includes TOM70 and $S A M 37$ that encode mitochondrial outer membrane proteins responsible for targeting proteins to mitochondria (Stojanovski et al. 2012). tom70 and sam374 mutations cause accumulation of unspliced tRNAs (Table 2; Fig. 2G,H; Supplemental Fig. S1). Although the heterotetrameric SEN complex is located on the mitochondrial cytoplasmic surface (Yoshihisa et al. 2003), the mechanisms for its localization, assembly, and function remain unknown. It is possible that Tom 70 and Sam 37 are required for proper localization or function of the SEN complex on mitochondria.

\section{Unanticipated phenotypes of alterations of genes involved in $t R N A$ biology}

We uncovered genes involved in tRNA biogenesis and/or processing that were not expected to affect accumulation of tRNA processing intermediates. One group in this category encodes aaRS. tRNA nuclear re-export by Msn5 requires that the tRNA cargo be spliced and aminoacylated (Huang and Hopper 2015); thus, one would anticipate that aaRS mutations would cause nuclear accumulation of mature cognate tRNAs but not defects in pre-tRNA processing. Contrary to this prediction, the Ile RS temperaturesensitive mutation (ils1-1) resulted in accumulation of end-processed unspliced tRNA ${ }^{\text {Ile }}$ UAU. More surprisingly, four aaRS-encoding genes also resulted in accumulation of noncognate end-processed unspliced tRNA ${ }^{\text {Ile }}$ UAU. The temperature-sensitive collections contain 16 of the 20 aaRS genes. Of these 16, only four (cdc60, frs $2, g \ln 4$, and ths1) cause accumulation of end-matured unspliced noncognate tRNA ${ }^{\text {Ile }}$ UAU (Table 2; Supplemental Figs. S2, S3). It is unknown what these aaRSs have in common or whether the unspliced tRNAs are located in the nucleus (which would occur via a defect in primary tRNA nuclear export) or the cytoplasm (which would occur if tRNAs or the SEN complex failed to reach mitochondria). It is also 
Wu et al.

Table 2. Novel genes that affect $t R N A$ processing

\begin{tabular}{|c|c|c|c|}
\hline Gene symbol & Essential/unessential & $\begin{array}{l}\text { Mutant } \\
\text { phenotypes }^{\mathrm{a}}\end{array}$ & Northern data location (figure number and gel number) \\
\hline \multicolumn{4}{|l|}{ Cytoskeleton } \\
\hline ACT1 & Essential & Type $4 / 5 / 6$ & $\begin{array}{l}\text { Fig. 2F; Supplemental Fig. S2, ABGel 73; Supplemental } \\
\text { Fig. S2-1, ABGel92 }\end{array}$ \\
\hline MYO2 & Essential & Type $4 / 5 / 6$ & $\begin{array}{l}\text { Supplemental Fig. S2, AB Gel 73; Supplemental } \\
\text { Fig. S2-1, ABGel } 92\end{array}$ \\
\hline PFY1 & Essential & Type $4 / 5 / 6$ & Supplemental Fig. S2, ABGel 73 \\
\hline \multicolumn{4}{|c|}{$\begin{array}{l}\text { Mitochondrial protein } \\
\text { targeting }\end{array}$} \\
\hline SAM37 & Unessential & Type 4/5/6 & Supplemental Fig. S1-2, JWGel 193L \\
\hline TOM70 & Unessential & Type 4/5/6 & Fig. 2G,H; Supplemental Fig. S1-3, JWGel 195 \\
\hline \multicolumn{4}{|r|}{ 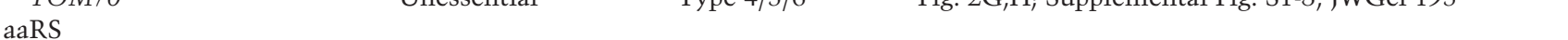 } \\
\hline ILS1 & Essential & Type 4/5/6 & Supplemental Fig. S2-1, KCGel \\
\hline CDC60 & Essential & Type 4/5/6 & Supplemental Fig. S2, ABGel 81 \\
\hline FRS2 & Essential & Type 4/5/6 & Supplemental Fig. S3 \\
\hline GLN4 & Essential & Type $4 / 5 / 6$ & Supplemental Fig. S3 \\
\hline THS1 & $\begin{array}{l}\text { Essential } \\
\text { Essential }\end{array}$ & Type $4 / 5 / 6$ & Supplemental Fig. S3 \\
\hline \multicolumn{4}{|c|}{ tRNA modification } \\
\hline DUS2 & Unessential & Type $1 / 2$ & Supplemental Fig. S1-2, JWGel 194 \\
\hline NCS2 & Unessential & Type $1 / 2$ & Supplemental Fig. S1-3, JWGel 195 \\
\hline SAP190 & Unessential & Type $1 / 2$ & Supplemental Fig. S1-3, JWGel 196 \\
\hline \multicolumn{4}{|c|}{ Pol III transcription } \\
\hline RPC11 & Essential & Type $1 / 2$ & Supplemental Fig. S3 \\
\hline$R P C 25$ & Essential & Type $1 / 2$ & Supplemental Fig. S3 \\
\hline RPO31 & Essential & Type $1 / 2$ & $\begin{array}{l}\text { Supplemental Fig. S2, ABGel 81; Supplemental } \\
\text { Fig. S2-1, ABGel 92 }\end{array}$ \\
\hline TFC 8 & Essential & Type $1 / 2$ & Supplemental Fig. S3 \\
\hline \multicolumn{4}{|c|}{$\begin{array}{l}\text { Histone acetylation and } \\
\text { deacetylation }\end{array}$} \\
\hline$B D F 1$ & Unessential & Type $1 / 2$ & Supplemental Fig. S1-3, JWGel 198 \\
\hline$E A F 7$ & Unessential & Type $1 / 2$ & Supplemental Fig. S1-3, JWGel 195 \\
\hline GCN5 & Unessential & Type $1 / 2$ & Fig. 2A; Supplemental Fig. S1-3, JWGel 199 \\
\hline HOS2 & Unessential & Type $1 / 2$ & Supplemental Fig. S1-2, JWGel 192 \\
\hline NGG1 & Unessential & Type $1 / 2$ & Supplemental Fig. S1-2, JWGel 192 \\
\hline SET3 & Unessential & Type $1 / 2$ & Supplemental Fig. S1-3, JWGel 196 \\
\hline SHG1 & Unessential & Type $1 / 2$ & Supplemental Fig. S1-2, JWGel 190 \\
\hline SPT8 & Unessential & Type $1 / 2$ & Supplemental Fig. S1, ABGel 119 \\
\hline UME6 & Unessential & Type $1 / 2$ & Supplemental Fig. S1-2, JWGel 192 \\
\hline YAF9 & Unessential & Type $1 / 2$ & Supplemental Fig. S1-3, JWGel 195 \\
\hline
\end{tabular}

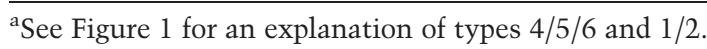

possible that this phenotype is due to novel functions of aaRSs (Guo et al. 2010).

Another group of genes known to be involved in tRNA biology, but not anticipated to affect tRNA processing, includes those encoding tRNA modification enzymes. Surprisingly, cells with mutations of DUS2, encoding a dihydrouridine synthetase, and NCS2 and SAP190, involved in $\mathrm{mcm}^{5} \mathrm{~s}^{2} \mathrm{U}_{34}$ modification of tRNA ${ }^{\mathrm{Lys}} \mathrm{UUU}$, $\mathrm{tRNA}{ }^{\mathrm{Glu}} \mathrm{UUC}$, and tRNA ${ }_{\text {GUG }}$ (Karlsborn et al. 2014), accumulate the tRNA ${ }^{\text {Ile }}$ UAU primary transcript (Table 2; Supplemental Fig. S1), although each encodes modification activities thought to reside exclusively in the cytoplasm (Hopper 2013), far from the nuclear location of tRNA end processing. For ncs $2 \Delta$ and sap $190 \Delta$ cells, the phenotypes may be due to the indirect role of $\mathrm{mcm}^{5} \mathrm{~s}^{2} \mathrm{U}_{34}$ in regulating translation of proteins involved in transcription and other processes (Karlsborn et al. 2014; Nedialkova and Leidel 2015).
Mutations of genes encoding Pol III transcription factors would be expected to cause decreased levels of primary tRNA transcripts and all subsequent intermediates in the processing pathway. In contrast to the expectation, we identified mutations of genes encoding Pol III subunits Rpc11, Rpc25, and Rpo31 and the Pol III transcription factor TFIIIC subunit Tfc8 that have increased levels of primary tRNA ${ }^{\text {Ile }}$ UAU transcripts (Table 2; Supplemental Figs. S2, S3). Another prominent GO category consists of the chromatin modification factors (Fig. 3C). Mutations of these cause the same phenotype of accumulation of the tRNA primary transcript (Table 2; Fig. 2A; Supplemental Fig. S1). We observed an overrepresentation of key subunits of the major histone acetylation (HAT) and deacetylation (HDAC) complexes, including Gcn5 and Ngg1 of the SAGA HAT complex, Eaf7 and Yaf9 of the NuA4 HAT complex, Hos 2 and Set 3 of the Set 3 HDAC complex, 
and Ume6, which recruits the Rpd3 HDAC complex to target elements (Kurdistani and Grunstein 2003).

In summary, through an unbiased genome-wide screen, we uncovered scores of novel gene products that are involved in tRNA processing and intracellular trafficking, providing insights into the complexity of tRNA biology, extensive links between tRNAs and various cellular processes, and likely pathways for tRNA nuclear export that function in parallel with Los1.

\section{Discussion}

As the first comprehensive analysis of the role of nearly the entire proteome in tRNA biology, this study discovered 174 gene products that function in tRNA transcription, processing, turnover, and subcellular movements. The percentage of essential genes identified is greater than the percentage of unessential genes identified, underscoring that essential genes more frequently participate in tRNA biology than unessential genes.

Given the scope of the mutant collection and the method applied, the screen is likely to have missed a fraction of gene products that play a role in tRNA biology. First, we would not be able to identity the genes whose mutants are not available in the collections used for the screen. For example, we did not find three of the four SEN complex subunits (Sen15, Sen34, and Sen54) (Trotta et al. 1997), as mutations of these genes do not exist in the mutant collections of essential genes. Second, duplicated genes or genes with redundant functions might not be identified; for example, GSP1 and GSP2, both of which encode Ran. Neither gsp1 $1 \Delta$ nor gsp2 $\Delta$ scored in our assay, even though Ran pathway defects cause accumulation of end-processed intron-containing tRNAs (Hopper et al. 1978; Kadowaki et al. 1993; Sarkar and Hopper 1998). Third, mutations of genes involved in tRNA retrograde import or re-export would not be revealed, as the imported tRNAs and cytoplasmic tRNAs are exactly the same size and cannot be differentiated by Northern analysis. Moreover, since this screen was conducted using only tRNA ${ }_{\text {UAU, we could }}^{\mathrm{Il}}$ have missed gene products specific for particular tRNA families. For example, $3^{\prime}$ end processing steps differ among tRNA families (Skowronek et al. 2014), and Thg1 catalyzes $\mathrm{a} \mathrm{G}^{-1}$ addition to only tRNA ${ }^{\text {His }}$ (Gu et al. 2003). Also, some steps in tRNA biology, such as generation of tRNA half molecules by Rny1, occur only under particular stress conditions (Thompson and Parker 2009); we would have missed mutations of the relevant genes because our screen was conducted for early log phase cells grown in rich YEPD medium. Furthermore, annotation errors in the MATa deletion collection could result in false negative results, as we did not perform the entire mutant hunt on the independent MATa deletion collection. Finally, we only screened protein-encoding genes, and it is possible that RNA-encoding genes might affect particular steps of tRNA biology. Nonetheless, this unbiased screen covered nearly all annotated yeast genes and revealed a role for 162 novel proteins in tRNA processing, intron turnover, and subcellular dynamics (Fig. 2B; Supplemental Figs. S1-S3; Supplemental Tables S1-S3).
Ran, NPC, and tRNA nuclear-cytoplasmic trafficking

A primary motivation for conducting this unbiased genome-wide screen was to gain understanding of the pathways for tRNA nuclear export and their mechanisms of action. This goal was met by the discoveries of Nups, a RanGTPase-associated protein, and two possible new nuclear export pathways for end-matured intron-containing tRNAs.

Nuclear-cytoplasmic transport of tRNAs occurs through nuclear pores composed of 30 Nups (Wente and Rout 2010). Six of the 22 available nucleoporin mutants accumulate end-matured unspliced tRNAs, including previously reported nup1334 (Sharma et al. 1996; Simos et al. 1996) and five Nups not previously known to affect tRNA nuclear export. These genes encode Nups present in nearly all NPC substructures-the inner ring (Nup170), outer ring (Nup133), transmembrane ring (Ndc1), symmetric FG Nups (Nup57), and cytoplasmic FG Nups (Nup159) (Wente and Rout 2010)_suggesting the importance of each substructure in tRNA export. Since less than half of the NPC components were found to affect tRNA splicing, the identified Nups may have more direct interactions with the tRNA export complex than other Nups. It is also possible that other unidentified Nups perform redundant functions in tRNA nuclear export and therefore did not score in the screen, as there is evidence for their functional redundancy (Terry and Wente 2009).

We uncovered mutants defective in the Ran-GTPase cycle-rna1-1 (RanGAP), prp20/srm1-ts (RanGEF), and yrb1-51 (RanBP) - to be defective in pre-tRNA splicing, further establishing, as anticipated, the role of the whole Ran GTPase cycle in tRNA nuclear export. Ran-binding importin- $\beta$ family members Los 1 and Msn5 function in tRNA nuclear export. los 1 mutants accumulate end-processed intron-containing tRNAs (Hopper et al. 1980) due to reduced primary tRNA nuclear export (Sarkar and Hopper 1998; Yoshihisa et al. 2003). Since Msn5 does not export intron-containing tRNAs (Huang and Hopper 2015), Los 1 is the only known protein for initial export of intron-containing tRNAs (Murthi et al. 2010). However, S. cerevisiae Los1, the Schizosaccharomyces pombe homolog Xpot, and the plant homolog PAUSED are all unessential for cell viability, supporting the existence of alternative tRNA nuclear export pathways in these organisms (Hurt et al. 1987; Li and Chen 2003; Cherkasova et al. 2012).

The four yeast members of the importin- $\beta$ family that serve as nuclear exportins (Los1 [exportin-t], Msn5 [exportin-5], Cse1 [CAS], and Crm1 [exportin-1]) are all represented in the mutant collections that we screened. Of these, Los1 and Crm1 affect tRNA biology, as assessed by Northern analysis. We identified Crm 1 as a possible exporter for intron-containing tRNAs. Like los1 $1 \Delta$ cells, crm1-1 temperature-sensitive mutants accumulate endmatured intron-containing tRNAs after the shift to the nonpermissive temperature. crm 1-1 cells rapidly accumulate the pre-tRNAs, suggesting a direct role of Crm1 in tRNA biology. Furthermore, crm1-1 los1 1 double mutant cells do not grow at temperatures at which either single 
mutant can grow, suggesting that cells require at least one of these pathways for tRNA nuclear export. We did not observe enhanced accumulation of end-matured intron-containing tRNAs in the crm1-1 los1 $\Delta$ double mutant (Fig. 4D, lanes 4,9) compared with the single mutants (Fig. $4 \mathrm{D}$, lanes $2,3,7,8)$. The reason for this is unknown, but one possibility is that other tRNA nuclear pathways (for example, the Met67/Mtr2 pathway) may be up-regulated in the double mutant to compensate for the loss of two exporters.

Curiously, crm1-1 cells accumulate tRNAs at the nuclear periphery, unlike rna1-1 and los $1 \Delta$ cells that accumulate tRNAs in the nucleoplasm. The staining pattern is similar to the pattern that we previously reported for the nucleoporin Nsp1 (Murthi and Hopper 2005). Possibly, there is a failure of tRNAs to move through the NPC or a failure to release tRNAs from the cytoplasmic face of the NPC in crm1-1 cells. Further in vivo biochemical studies to investigate direct interaction of end-matured intron-containing tRNAs with Crm 1 are required to unravel its role in tRNA nuclear-cytoplasmic dynamics.

Mex67 and Mtr2 are components of the nuclear export machinery of mRNAs, 60 S ribosomal subunit, and the telomerase RNA (Yao et al. 2007; Wu et al. 2014). We found that mex67-ts5 and mtr2 mutants accumulate end-matured intron-containing tRNAs, the same phenotype as los1 1 and crm1-1 cells (Hopper et al. 1980; Sarkar and Hopper 1998). Future studies are required to test the tantalizing possibility that the Mex67/Mtr2 complex provides another nuclear export pathway for tRNAs. In sum, a major discovery from this work is the possibility that three pathways operate in parallel to export introncontaining pre-tRNAs from the nucleus to the cytoplasm (Fig. 1A).

Targeting $t R N A s$ and the SEN complex to mitochondria for $t R N A$ splicing

Unlike the human SEN complex that is located in the nucleus (Paushkin et al. 2004), the yeast SEN complex is located on the outer surface of mitochondria (Yoshihisa et al. 2003). Therefore, after nuclear export, intron-containing tRNAs must locate to mitochondria. However, no gene products have previously been implicated in this process. We identified mutations of three genes encoding cytoskeleton proteins that accumulate end-matured intron-containing tRNAs. These proteins include actin, a myosin V motor (Myo2), and profilin (Pfy1). Actin-mediated RNA subcellular transport requires myosins. Yeast has two myosin V motors: Myo2 and Myo4. Myo4 functions in delivery of ASH1 mRNA to daughter cells (Takizawa et al. 1997). Possibly, Myo2 has a similar function for tRNA transport to mitochondria. In Drosophila, profilin is required for localizing the oskar mRNA to the posterior pole of the developing oocyte (Manseau et al. 1996), and so Pfy1 may also serve in tRNA subcellular dynamics. It is also possible that these proteins are involved in proper localization and function of the SEN complex or their encoding mRNAs to mitochondria.
The mechanisms for targeting each of the four subunits of SEN to mitochondria for proper assembly and function of the SEN complex remain unclear. We identified two genes encoding mitochondrial outer membrane proteins (TOM70 and SAM37) that participate in targeting proteins to mitochondria (Stojanovski et al. 2012). We are examining the hypothesis that they are required for the proper localization of the SEN subunits to the mitochondria surface.

\section{Links between $t R N A$ s and other cellular processes}

Our screen results also revealed links between tRNAs and many other cellular processes, such as histone acetylation/deactylation. It is remarkable that the identified HAT and HDAC genes are related to each other physically and genetically (Lin et al. 2008) and that mutations of these genes cause the same result: accumulation of primary tRNA transcripts. While understanding the biological relevance of HAT and HDAC proteins requires further investigation, an interesting possibility is that these proteins ensure the chromatin organization needed for proper localization of tRNA genes in the nucleolus (Thompson et al. 2003) or access to the tRNA $5^{\prime}$ end processing enzyme RNase P (Bertrand et al. 1998).

In conclusion, our genome-wide screen discovered 162 novel gene products involved in tRNA biology, 116 of which have human orthologs. These include two possible novel tRNA nuclear exporters (Crm1 and Mex67/Mtr2), new roles of genes known to affect tRNAs, and links between tRNA biology and various cellular processes. The results not only depict a global view of tRNA biology in yeast but also could provide insights into tRNA biology in other higher organisms. Future work will be needed to address the roles of the identified gene products in tRNA biogenesis and subcellular movement.

\section{Materials and methods}

\section{Strains}

The S. cerevisiae MATa deletion collection (BY4741 background:

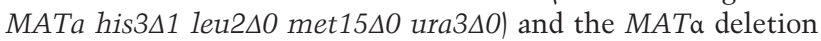

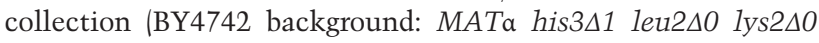
ura3 $\Delta 0$ ) were purchased from Open Biosystems. Two temperature-sensitive collections were gifts from Dr. C. Boone and Dr. P. Hieter. The xpo1-1 temperature-sensitive strain was a gift from Dr. C. Guthrie. The yeast genomic tiling collection was purchased from Open Biosystems. The MoBY-ORF library was purchased from Thermo Scientific Open Biosystems. Standard methods for culturing yeast were used.

\section{High-throughput small RNA isolation and Northern analysis}

Yeast mutant strains were grown in the 96-deep-well plates in YEPD to early log phase, and small RNAs were isolated using a high-throughput RNA isolation method described previously (Wu et al. 2013). The temperature-sensitive mutants were shifted to nonpermissive temperature $\left(37^{\circ} \mathrm{C}\right)$ for $2 \mathrm{~h}$ before RNA extraction. tRNAs were analyzed by a nonradioactive Northern method 
using DIG-labeled probes as described (Wu et al. 2013) using probes 1 and KC031 (see the Supplemental Material).

\section{Growth assays}

Five microliters of aliquots from serial dilutions of the indicated yeast cell cultures was spotted on rich or selective medium. The plates were incubated for $2 \mathrm{~d}$ at the indicated temperatures.

\section{FISH}

Cells were grown in $15 \mathrm{~mL}$ of medium overnight at $23^{\circ} \mathrm{C}$ to early $\log$ phase $\left(\mathrm{OD}_{600}=0.15-0.3\right)$. Temperature-sensitive cells were shifted to $37^{\circ} \mathrm{C}$ for 2 or $4 \mathrm{~h}$ before $\mathrm{OD}_{600}$ reached 0.3 . Cells were collected, and FISH was performed as previously described using probe SRIM15 for tRNA ${ }^{\text {Tyr }}$ (Sarkar and Hopper 1998) with the previously described modifications (Stanford et al. 2004). Images were captured using a Nikon microscope equipped with an UltraView Vox spinning disk confocal apparatus (PerkinElmer Life and Analytical Science) and a cooled charge-coupled device camera (Orca-AG, Hamamatsu). tRNA signals were visualized using a 561-nm (red) argon ion laser, and DNA was stained by DAPI and visualized using a 405-nm (blue) laser and a 60×/1.4 NA objective lens. Images were captured using Volocity software and $\mathrm{Na}-$ tional Institutes of Health ImageJ and assembled using Adobe Photoshop C6.

\section{Oligonucleotides}

The sequences of the oligonucleotides used are provided in the Supplemental Material.

\section{Acknowledgments}

We thank A.K.H. laboratory members for excellent scientific interactions, especially Dr. H.-Y. Huang for her initial effort to screen the deletion collection, Ms. C. Shepard and Ms. H. Osborn for aiding the screen, Dr. R. Hurto and Mr. J. Hale for generating the crm1-1 los1 $\Delta$ mutant, and Dr. H.-Y. Chu for valuable advice. We are grateful to Dr. C. Boone and Dr. P. Hieter for providing the temperature-sensitive collections. This work was supported by National Institutes of Health grant GM27930 to A.K.H., and The Ohio State University Pelotonia Graduate Fellowship to J.W.

\section{References}

Aebi M, Kirchner G, Chen JY, Vijayraghavan U, Jacobson A, Martin NC, Abelson J. 1990. Isolation of a temperature-sensitive mutant with an altered tRNA nucleotidyltransferase and cloning of the gene encoding tRNA nucleotidyltransferase in the yeast Saccharomyces cerevisiae. I Biol Chem 265: 16216-16220.

Ben-Aroya S, Coombes C, Kwok T, O'Donnell KA, Boeke JD, Hieter P. 2008. Toward a comprehensive temperature-sensitive mutant repository of the essential genes of Saccharomyces cerevisiae. Mol Cell 30: 248-258.

Ben-Shitrit T, Yosef N, Shemesh K, Sharan R, Ruppin E, Kupiec M. 2012. Systematic identification of gene annotation errors in the widely used yeast mutation collections. Nat Methods 9: 373-378.

Bertrand E, Houser-Scott F, Kendall A, Singer RH, Engelke DR. 1998. Nucleolar localization of early tRNA processing. Genes Dev 12: 2463-2468.
Boeke JD, LaCroute F, Fink GR. 1984. A positive selection for mutants lacking orotidine- $5^{\prime}$-phosphate decarboxylase activity in yeast: 5-fluoro-orotic acid resistance. Mol Gen Genet 197: 345-346.

Buxbaum AR, Haimovich G, Singer RH. 2015. In the right place at the right time: visualizing and understanding mRNA localization. Nat Rev Mol Cell Biol 16: 95-109.

Cherkasova V, Maury LL, Bacikova D, Pridham K, Bähler J, Maraia RJ. 2012. Altered nuclear tRNA metabolism in La-deleted Schizosaccharomyces pombe is accompanied by a nutritional stress response involving Atflp and Pcrlp that is suppressible by Xpo-t/Los1p. Mol Biol Cell 23: 480-491.

Chernyakov I, Whipple JM, Kotelawala L, Grayhack EJ, Phizicky EM. 2008. Degradation of several hypomodified mature tRNA species in Saccharomyces cerevisiae is mediated by Met22 and the $5^{\prime}-3^{\prime}$ exonucleases Ratl and Xrn1. Genes Dev 22: 1369-1380.

Cherry JM, Hong EL, Amundsen C, Balakrishnan R, Binkley G, Chan ET, Christie KR, Costanzo MC, Dwight SS, Engel SR, et al. 2012. Saccharomyces Genome Database: the genomics resource of budding yeast. Nucleic Acids Res 40: D700-D705.

Fornerod M, Ohno M, Yoshida M, Mattaj IW. 1997. CRM1 is an export receptor for leucine-rich nuclear export signals. Cell 90: $1051-1060$.

Frank DN, Pace NR. 1998. Ribonuclease P: unity and diversity in a tRNA processing ribozyme. Annu Rev Biochem 67: 153-180.

Giaever G, Chu AM, Ni L, Connelly C, Riles L, Veronneau S, Dow S, Lucau-Danila A, Anderson K, Andre B, et al. 2002. Functional profiling of the Saccharomyces cerevisiae genome. $\mathrm{Na}$ ture 418: 387-391.

Gorlich D, Kutay U. 1999. Transport between the cell nucleus and the cytoplasm. Annu Rev Cell Dev Biol 15: 607-660.

Grunenfelder B, Winzeler EA. 2002. Treasures and traps in genome-wide data sets: case examples from yeast. Nat Rev Genet 3: 653-661.

Gu W, Jackman JE, Lohan AJ, Gray MW, Phizicky EM. 2003. tRNAHis maturation: an essential yeast protein catalyzes addition of a guanine nucleotide to the $5^{\prime}$ end of tRNAHis. Genes Dev 17: 2889-2901.

Guo M, Yang XL, Schimmel P. 2010. New functions of aminoacyl-tRNA synthetases beyond translation. Nat Rev Mol Cell Biol 11: 668-674.

Ho CH, Magtanong L, Barker SL, Gresham D, Nishimura S, Natarajan P, Koh JL, Porter J, Gray CA, Andersen RJ, et al. 2009. A molecular barcoded yeast ORF library enables mode-of-action analysis of bioactive compounds. Nat Biotechnol 27: 369-377.

Hopper AK. 2013. Transfer RNA post-transcriptional processing, turnover, and subcellular dynamics in the yeast Saccharomyces cerevisiae. Genetics 194: 43-67.

Hopper AK, Banks F, Evangelidis V. 1978. A yeast mutant which accumulates precursor tRNAs. Cell 14: 211-219.

Hopper AK, Schultz LD, Shapiro RA. 1980. Processing of intervening sequences: a new yeast mutant which fails to excise intervening sequences from precursor tRNAs. Cell 19: 741-751.

Huang HY, Hopper AK. 2015. In vivo biochemical analyses reveal distinct roles of $\beta$-importins and eEF1A in tRNA subcellular traffic. Genes Dev 29: 772-783.

Hurt DJ, Wang SS, Lin YH, Hopper AK. 1987. Cloning and characterization of LOS1, a Saccharomyces cerevisiae gene that affects tRNA splicing. Mol Cell Biol 7: 1208-1216.

Jones GM, Stalker J, Humphray S, West A, Cox T, Rogers J, Dunham I, Prelich G. 2008. A systematic library for 
comprehensive overexpression screens in Saccharomyces cerevisiae. Nat Methods 5: 239-241.

Kadaba S, Krueger A, Trice T, Krecic AM, Hinnebusch AG, Anderson J. 2004. Nuclear surveillance and degradation of hypomodified initiator tRNAMet in S. cerevisiae. Genes Dev 18: 1227-1240.

Kadowaki T, Goldfarb D, Spitz LM, Tartakoff AM, Ohno M. 1993. Regulation of RNA processing and transport by a nuclear guanine nucleotide release protein and members of the Ras superfamily. EMBO J 12: 2929-2937.

Karlsborn T, Tukenmez H, Mahmud AK, Xu F, Xu H, Bystrom AS. 2014. Elongator, a conserved complex required for wobble uridine modifications in Eukaryotes. RNA Biol 11: 15191528.

Kirchner S, Ignatova Z. 2015. Emerging roles of tRNA in adaptive translation, signalling dynamics and disease. Nat Rev Genet 16: 98-112.

Kurdistani SK, Grunstein M. 2003. Histone acetylation and deacetylation in yeast. Nat Rev Mol Cell Biol 4: 276-284.

Li J, Chen X. 2003. PAUSED, a putative exportin-t, acts pleiotropically in Arabidopsis development but is dispensable for viability. Plant Physiol 132: 1913-1924.

Li Z, Vizeacoumar FJ, Bahr S, Li J, Warringer J, Vizeacoumar FS, Min R, Vandersluis B, Bellay J, Devit M, et al. 2011. Systematic exploration of essential yeast gene function with temperature-sensitive mutants. Nat Biotechnol 29: 361-367.

Lin YY, Qi Y, Lu JY, Pan X, Yuan DS, Zhao Y, Bader JS, Boeke JD. 2008. A comprehensive synthetic genetic interaction network governing yeast histone acetylation and deacetylation. Genes Dev 22: 2062-2074.

Manseau L, Calley J, Phan H. 1996. Profilin is required for posterior patterning of the Drosophila oocyte. Development 122: 2109-2116.

Murthi A, Hopper AK. 2005. Genome-wide screen for inner nuclear membrane protein targeting in Saccharomyces cerevisiae: roles for $\mathrm{N}$-acetylation and an integral membrane protein. Genetics 170: 1553-1560.

Murthi A, Shaheen HH, Huang HY, Preston MA, Lai TP, Phizicky EM, Hopper AK. 2010. Regulation of tRNA bidirectional nuclear-cytoplasmic trafficking in Saccharomyces cerevisiae. Mol Biol Cell 21: 639-649.

Nedialkova DD, Leidel SA. 2015. Optimization of codon translation rates via tRNA modifications maintains proteome integrity. Cell 161: 1606-1618.

Nino CA, Herissant L, Babour A, Dargemont C. 2013. mRNA nuclear export in yeast. Chem Rev 113: 8523-8545.

Paushkin SV, Patel M, Furia BS, Peltz SW, Trotta CR. 2004. Identification of a human endonuclease complex reveals a link between tRNA splicing and pre-mRNA $3^{\prime}$ end formation. Cell 117: 311-321.

Phizicky EM, Hopper AK. 2010. tRNA biology charges to the front. Genes Dev 24: 1832-1860.

Pluta K, Lefebvre O, Martin NC, Smagowicz WJ, Stanford DR, Ellis SR, Hopper AK, Sentenac A, Boguta M. 2001. Maf1p, a negative effector of RNA polymerase III in Saccharomyces cerevisiae. Mol Cell Biol 21: 5031-5040.

Sarkar S, Hopper AK. 1998. tRNA nuclear export in saccharomyces cerevisiae: in situ hybridization analysis. Mol Biol Cell 9: 3041-3055.

Sharma K, Fabre E, Tekotte H, Hurt EC, Tollervey D. 1996. Yeast nucleoporin mutants are defective in pre-tRNA splicing. Mol Cell Biol 16: 294-301.

Sharma S, Langhendries JL, Watzinger P, Kotter P, Entian KD, Lafontaine DL. 2015. Yeast Kre33 and human NAT10 are con- served 18S rRNA cytosine acetyltransferases that modify tRNAs assisted by the adaptor Tan1/THUMPD1. Nucleic Acids Res 43: 2242-2258.

Simos G, Tekotte H, Grosjean H, Segref A, Sharma K, Tollervey D, Hurt EC. 1996. Nuclear pore proteins are involved in the biogenesis of functional tRNA. EMBO J 15: 2270-2284.

Skowronek E, Grzechnik P, Spath B, Marchfelder A, Kufel J. 2014. tRNA $3^{\prime}$ processing in yeast involves tRNase $\mathrm{Z}$, Rexl, and Rrp6. RNA 20: 115-130.

Stade K, Ford CS, Guthrie C, Weis K. 1997. Exportin 1 (Crmlp) is an essential nuclear export factor. Cell 90: 1041-1050.

Stanford DR, Whitney ML, Hurto RL, Eisaman DM, Shen WC, Hopper AK. 2004. Division of labor among the yeast Sol proteins implicated in tRNA nuclear export and carbohydrate metabolism. Genetics 168: 117-127.

Stojanovski D, Bohnert M, Pfanner N, van der Laan M. 2012. Mechanisms of protein sorting in mitochondria. Cold Spring Harb Perspect Biol 4: a011320.

Takano A, Kajita T, Mochizuki M, Endo T, Yoshihisa T. 2015. Cytosolic Hsp70 and co-chaperones constitute a novel system for tRNA import into the nucleus. Elife 4: e04659.

Takizawa PA, Sil A, Swedlow JR, Herskowitz I, Vale RD. 1997. Actin-dependent localization of an RNA encoding a cell-fate determinant in yeast. Nature 389: 90-93.

Terry LJ, Wente SR. 2009. Flexible gates: dynamic topologies and functions for FG nucleoporins in nucleocytoplasmic transport. Eukaryot Cell 8: 1814-1827.

Thompson DM, Parker R. 2009. The RNase Rnylp cleaves tRNAs and promotes cell death during oxidative stress in Saccharomyces cerevisiae. J Cell Biol 185: 43-50.

Thompson M, Haeusler RA, Good PD, Engelke DR. 2003. Nucleolar clustering of dispersed tRNA genes. Science 302: 1399-1401.

Trotta CR, Miao F, Arn EA, Stevens SW, Ho CK, Rauhut R, Abelson JN. 1997. The yeast tRNA splicing endonuclease: a tetrameric enzyme with two active site subunits homologous to the archaeal tRNA endonucleases. Cell 89: 849-858.

Wente SR, Rout MP. 2010. The nuclear pore complex and nuclear transport. Cold Spring Harb Perspect Biol 2: a000562.

Winzeler EA, Shoemaker DD, Astromoff A, Liang H, Anderson K, Andre B, Bangham R, Benito R, Boeke JD, Bussey H, et al. 1999. Functional characterization of the $S$. cerevisiae genome by gene deletion and parallel analysis. Science 285: 901-906.

Woolford JL Jr, Baserga SJ. 2013. Ribosome biogenesis in the yeast Saccharomyces cerevisiae. Genetics 195: 643-681.

Wu J, Hopper AK. 2014. Healing for destruction: tRNA intron degradation in yeast is a two-step cytoplasmic process catalyzed by tRNA ligase Rlg1 and $5^{\prime}$-to-3' exonuclease Xrn1. Genes Dev 28: 1556-1561.

Wu J, Huang HY, Hopper AK. 2013. A rapid and sensitive non-radioactive method applicable for genome-wide analysis of Saccharomyces cerevisiae genes involved in small RNA biology. Yeast (Chichester, England) 30: 119-128.

Wu H, Becker D, Krebber H. 2014. Telomerase RNA TLC1 shuttling to the cytoplasm requires mRNA export factors and is important for telomere maintenance. Cell Rep 8: 1630-1638.

Yao W, Roser D, Kohler A, Bradatsch B, Bassler J, Hurt E. 2007. Nuclear export of ribosomal 60S subunits by the general mRNA export receptor Mex67-Mtr2. Mol Cell 26: 51-62.

Yoshihisa T, Yunoki-Esaki K, Ohshima C, Tanaka N, Endo T. 2003. Possibility of cytoplasmic pre-tRNA splicing: the yeast tRNA splicing endonuclease mainly localizes on the mitochondria. Mol Biol Cell 14: 3266-3279. 


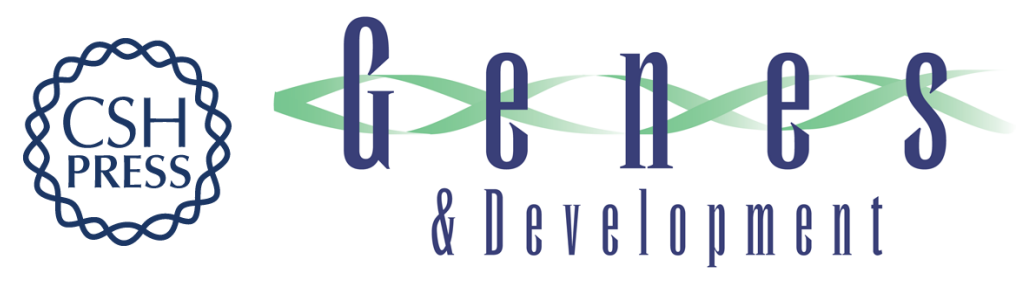

\section{Genome-wide screen uncovers novel pathways for tRNA processing and nuclear-cytoplasmic dynamics}

Jingyan Wu, Alicia Bao, Kunal Chatterjee, et al.

Genes Dev. 2015, 29:

Access the most recent version at doi:10.1101/gad.269803.115

\section{Supplemental http://genesdev.cshlp.org/content/suppl/2015/12/17/29.24.2633.DC1 \\ Material}

References This article cites 61 articles, 29 of which can be accessed free at:

http://genesdev.cshlp.org/content/29/24/2633.full.html\#ref-list-1

Creative This article is distributed exclusively by Cold Spring Harbor Laboratory Press for the first

Commons six months after the full-issue publication date (see

License http://genesdev.cshlp.org/site/misc/terms.xhtml). After six months, it is available under a Creative Commons License (Attribution-NonCommercial 4.0 International), as described at http://creativecommons.org/licenses/by-nc/4.0/.

Email Alerting Receive free email alerts when new articles cite this article - sign up in the box at the top Service right corner of the article or click here.

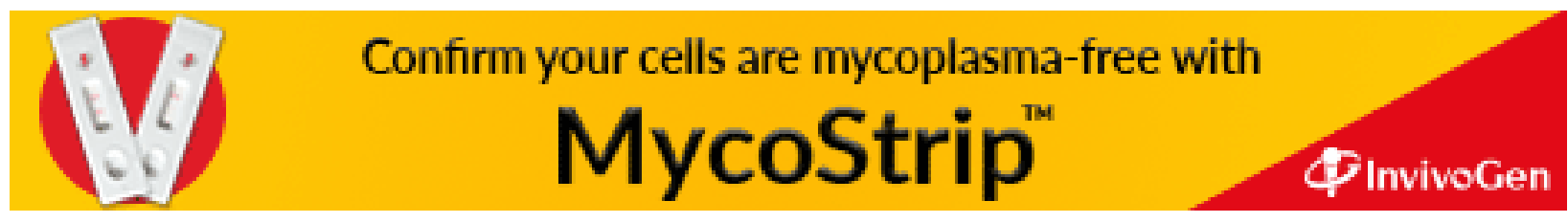

